\title{
Precise Study on Size-Dependent Properties of Magnetic Iron Oxide Nanoparticles for In Vivo Magnetic Resonance Imaging
}

\author{
Ling Chen, ${ }^{1}$ Jun Xie, ${ }^{1,2}$ Haoan Wu $\mathbb{D},{ }^{1}$ Jianzhong $\mathrm{Li}^{3}{ }^{3}$ Zhiming Wang, ${ }^{1}$ Lina Song $\mathbb{D},{ }^{4}$ \\ Fengchao Zang, ${ }^{5}$ Ming Ma $\mathbb{D}^{1},{ }^{1}$ Ning Gu ${ }^{D},{ }^{1}$ and Yu Zhang $\mathbb{D}^{1}$ \\ ${ }^{1}$ State Key Laboratory of Bioelectronics, Jiangsu Key Laboratory for Biomaterials and Devices, School of Biological Science and \\ Medical Engineering and Collaborative Innovation Center of Suzhou Nano Science and Technology, Southeast University, \\ Nanjing 210096, China \\ ${ }^{2}$ School of Life Science, Jiangsu Normal University, Xuzhou 221116, China \\ ${ }^{3}$ Department of Nephrology, The First Affiliated Hospital of Soochow University, Suzhou 215006, China \\ ${ }^{4}$ Department of Radiology, The Affiliated Hospital of Nanjing University of Chinese Medicine, Nanjing 210029, China \\ ${ }^{5}$ Jiangsu Key Laboratory of Molecular and Functional Imaging Medical School, Southeast University, Nanjing 210096, China
}

Correspondence should be addressed to Ning Gu; guning@seu.edu.cn and Yu Zhang; zhangyu@seu.edu.cn

Received 22 February 2018; Revised 24 April 2018; Accepted 14 May 2018; Published 28 May 2018

Academic Editor: Jean M. Greneche

Copyright (c) 2018 Ling Chen et al. This is an open access article distributed under the Creative Commons Attribution License, which permits unrestricted use, distribution, and reproduction in any medium, provided the original work is properly cited.

\begin{abstract}
Developing a biocompatible contrast agent with high stability and favorable magnetism for sensitive detection of malignant tumors using magnetic resonance imaging (MRI) remains a great demand in clinical. Nowadays, the fine control of magnetic iron oxide nanoparticle (MION) sizes from a few nanometers to dozens of nanometers can be realized through a thermal decomposition method of iron precursors. This progress allows us to research accurately on the size dependence of magnetic properties of MION, involving saturation magnetization $\left(M_{\mathrm{s}}\right)$, specific absorption rate (SAR), and relaxivity. Here, we synthesized MION in a size range between 14 and $26 \mathrm{~nm}$ and modified them with DSPE-PEG2000 for biomedical use. The magnetic properties of PEGylated MION increased monotonically with MION size, while the nonspecific uptake of MION also enhanced with size through cell experiments. The MION with the size of $22 \mathrm{~nm}$ as a T2-weighted contrast agent presented the best contrastenhancing effect comparing with other sizes in vivo MRI of murine tumor. Therefore, the MION of $22 \mathrm{~nm}$ may have potential to serve as an ideal MRI contrast agent for tumor detection.
\end{abstract}

\section{Introduction}

Over the past few decades, numerous researches have focused on nanomaterials for biomedical applications, among which magnetic iron oxide nanoparticles (MIONs) have become the most promising candidate owing to their excellent biocompatibility and outstanding magnetic properties. The magnetic nanoparticles have been widely applied to in vivo use, such as magnetic resonance imaging (MRI) [1-3], magnetic-induced hyperthermia [4, 5], switching cellular activity [6-8], or magnetically guided drug/gene delivery [9-11]. Among them, MRI is one of the key applications in which magnetic nanoparticles are used as contrast-enhancing agents for improving the sensitivity of
MRI. Moreover, several iron oxide nanoparticles including Feridex and Resovist have been approved as contrast agents for $\mathrm{T}_{2}$-weighted MR imaging in clinical for years. Nevertheless, due to their synthetic method of coprecipitation, the products are polydisperse with low crystallinity, which results in relatively inferior magnetic properties. Benefit from the introduction of a thermal decomposition method, uniform iron oxide nanoparticles with high crystallinity and controlled sizes can be synthesized through adjusting the molar ratios of surfactants used in the reaction [12], which made it possible to do a precise study on properties of iron oxide nanoparticles with different sizes.

Previous reports showed that magnetic properties of iron oxide nanoparticles such as saturation magnetization $\left(M_{\mathrm{s}}\right)$, 
specific absorption rate (SAR), and relaxivity $\left(r_{2}\right)$ have a close relationship with their sizes among a large size range from a few nanometers to hundreds of nanometers [2, 13-17]. Tong et al. [16] reported that the $M_{\mathrm{s}}$ of MION increased slightly with size from 6 to $40 \mathrm{~nm}$, and the SAR values increased monotonically with size enlarged $(325 \mathrm{kHz}$, $20.7 \mathrm{kA} / \mathrm{m}$ ), while SAR was really low for MION below $11 \mathrm{~nm}$. In another study, the SAR values of $\mathrm{Fe}_{3} \mathrm{O}_{4}$ nanoparticles synthesized by coprecipitation with diameters from 7.5 to $416 \mathrm{~nm}$ were measured under an external alternating magnetic field $(80 \mathrm{kHz}, 32.5 \mathrm{kA} / \mathrm{m})$, and the nanoparticles of $46 \mathrm{~nm}$ exhibited the highest SAR [13]. Lartigue et al. [15] prepared sugar-coated iron oxide nanoparticles, and the SAR values $(168 \mathrm{kHz}, 21 \mathrm{kA} / \mathrm{m})$ gradually increased from 4 to $35 \mathrm{~nm}$, meanwhile the $r_{2}$ values also enlarged from 4 to $18 \mathrm{~nm}$, while the nanoparticles of $35 \mathrm{~nm}$ were excluded from use in MRI because of the precipitation problems which may cause risks of thrombosis in clinical. On the basis of these results, it was concluded that the magnetic properties $\left(M_{\mathrm{s}}, \mathrm{SAR}\right.$, and $\left.r_{2}\right)$ were relatively low for small sizes of the MION below $14 \mathrm{~nm}$. In addition, the interaction between particles enhanced with their size increased, which will result in aggregation and instability in solution. Owing to these reasons, this study will focus on MION with size from 14 to $26 \mathrm{~nm}$ for suitable in vivo applications used as MRI contrast agents.

It is noteworthy that understanding and controlling of their properties is extremely important for effective in vivo application of MION. In addition, as MRI contrastenhancing agents, it is essential for MION to possess good magnetic behavior as well as biocompatible surface. As the products of thermal decomposition need further surface modification to be water-soluble, amphiphilic molecular DSPEPEG is one of the common choices which can make the MION singly encapsulated in water solution [18]. The PEGylation of MION with DSPE-PEG cannot only provide a stable layer to prevent agglomeration but also dramatically reduce nonspecific uptake by macrophages and improve blood circulation time when in a physiological environment. According to the previous report, the endocytosis of nanoparticles was sizedependent [19], so it is necessary to evaluate the antiphagocytosis ability of the MION with different sizes for in vivo uses.

In this work, we report a precise study on size-dependent properties of MION synthesized by a thermal decomposition method capable of yielding nanoparticles in a size range between 14 and $26 \mathrm{~nm}$ as a $\mathrm{T}_{2}$-weighted contrast agent for MRI. Herein, the synthesized MIONs were first decorated with DSPE-PEG2000 before performance measurements. Our study demonstrated that the properties of MION such as $M_{s}$, SAR, and $r_{2}$ relaxivity were all dependent on size and enhanced monotonically with MION size from 14 to $26 \mathrm{~nm}$. In vitro cell experiments indicated that the nonspecific uptake of MION by macrophages was also in a sizedependent way. The in vivo MRI of murine tumor elucidated the availability of MION as $\mathrm{T}_{2}$-weighted contrast-enhancing agents, especially for the MION of $22 \mathrm{~nm}$ which was proven to present the best imaging effect. As a result, the size of $22 \mathrm{~nm}$ may be the most appropriate selection used for in vivo MRI.

\section{Experimental}

2.1. Materials. $\mathrm{Fe}(\mathrm{acac})_{3}$ was bought from Sigma-Aldrich (USA). Benzyl ether was obtained from Alfa Aesar (USA). Oleic acid (OA) and oleylamine (OAm) were purchased from Damas-beta (China). DSPE-PEG2000 was bought from A.V.T. (Shanghai) Pharmaceutical Co. Ltd. (China). Murine breast cells (4T1), human umbilical vein endothelial cells (HUVECs), and murine macrophage cells (RAW264.7) were purchased from the Type Culture Collection of the Chinese Academy of Sciences (China).

2.2. Synthesis of Size-Controlled Magnetic Iron Oxide Nanoparticles. The hydrophobic magnetic iron oxide nanoparticles $\left(\mathrm{Fe}_{3} \mathrm{O}_{4} @ \mathrm{OA}\right)$ were synthesized by thermal decomposition of $\mathrm{Fe}(\mathrm{acac})_{3}$ according to literature $[12,20]$. The size-controlled MIONs were produced by adjusting the molar ratios of OA to OAm. In synthesis of MION of 14, 18,22 , and $26 \mathrm{~nm}$, a $100 \mathrm{ml}$ three-neck flask was prepared with $2 \mathrm{mmol} \mathrm{Fe}(\mathrm{acac})_{3}$ and $20 \mathrm{ml}$ benzyl ether inside, $9 \mathrm{mmol}$ $\mathrm{OA}$ and $3 \mathrm{mmol} \mathrm{OAm}, 8 \mathrm{mmol} \mathrm{OA}$ and $4 \mathrm{mmol} \mathrm{OAm}$, $7.5 \mathrm{mmol} \mathrm{OA}$ and $4.5 \mathrm{mmol} \mathrm{OAm}$, or $6 \mathrm{mmol} \mathrm{OA}$ and $6 \mathrm{mmol}$ OAm were added, respectively. Under the protection of $\mathrm{N}_{2}$ with an appropriate flow, the mixture was first heated to $220^{\circ} \mathrm{C}$ in $1 \mathrm{~h}$ at a heating rate of $3.3^{\circ} \mathrm{C} / \mathrm{min}$ and kept at $220^{\circ} \mathrm{C}$ for $1 \mathrm{~h}$, then heated to $290^{\circ} \mathrm{C}$ in $30 \mathrm{~min}$ and maintained this temperature for $30 \mathrm{~min}$. After reaction finished, the product was transferred to a beaker of $250 \mathrm{ml}$ and washed 3 times by ethanol on the magnet. Lastly, the synthetic $\mathrm{Fe}_{3} \mathrm{O}_{4} @ \mathrm{OA}$ were dispersed in chloroform in a conical flask and stored in room temperature.

2.3. PEGylation of Iron Oxide Nanoparticles with Different Sizes. As the oleic acid- (OA-) coated MIONs were hydrophobic, they need further modification with biocompatible material to be bioavailable. Herein, DSPE-PEG2000 which was approved by FDA for clinical application was used to decorate $\mathrm{Fe}_{3} \mathrm{O}_{4} @ \mathrm{OA}$ according to our previous work with some modifications [20-22]. For PEGylation of MION with different sizes of $14,18,22$, and $26 \mathrm{~nm}$, DSPE-PEG2000 dissolved in $3 \mathrm{ml}$ chloroform at the concentration of 17,13 , 10 , or $8 \mathrm{mg} / \mathrm{ml}$ was, respectively, placed in a $25 \mathrm{ml}$ roundbottom flask, mixing with $10 \mathrm{mg}$ (Fe content) $\mathrm{Fe}_{3} \mathrm{O}_{4} @ \mathrm{OA}$ dissolved in $3 \mathrm{ml}$ chloroform by ultrasonic dissolving. Six milliliters deionized water was then added and mixed with the reactant. The reaction was proceeded $\left(70^{\circ} \mathrm{C}\right.$ for $\left.10 \mathrm{~min}\right)$ using a rotary evaporator to remove the chloroform completely. Magnetic separation method was then applied to purify the resultant water-soluble MION ( $\left.\mathrm{Fe}_{3} \mathrm{O}_{4} @ \mathrm{PEG}\right)$ by eliminating the empty lipid micelles simultaneously formed during the course of PEGylation. After purification, $\mathrm{Fe}_{3} \mathrm{O}_{4} @ P E G$ of different sizes were stored at $4{ }^{\circ} \mathrm{C}$.

2.4. Characterization of $\mathrm{Fe}_{3} \mathrm{O}_{4} @ \mathrm{OA}$ and $\mathrm{Fe}_{3} \mathrm{O}_{4} @ P E G$. Transmission electron microscopy (TEM, JEOL, Tokyo, Japan) was used to identify the morphology of $\mathrm{Fe}_{3} \mathrm{O}_{4} @ \mathrm{OA}$ and $\mathrm{Fe}_{3} \mathrm{O}_{4} @ \mathrm{PEG}$ with four sizes. The TEM samples of $\mathrm{Fe}_{3} \mathrm{O}_{4} @$ PEG were prepared by negative staining with 2\% phosphotungstic acid to observe the lipid layer outside the iron oxide nanoparticle core. The iron concentration of 
$\mathrm{Fe}_{3} \mathrm{O}_{4} @ P E G$ solution was evaluated using an ultravioletvisible spectrophotometer (Shimadzu UV-3600, Japan) [23]. The hysteresis curve of $\mathrm{Fe}_{3} \mathrm{O}_{4} @ P E G$ was investigated by a VSM (Lake Shore Cryotronics, Model 7407, USA) at room temperature; all samples were measured in water solution form. The average size measurement of $\mathrm{Fe}_{3} \mathrm{O}_{4} @ P E G$ was conducted using a dynamic light scattering analyzer (Malvern, ZS90, UK). The in vitro MRI and the related $\mathrm{T}_{2}$ relaxation time of $\mathrm{Fe}_{3} \mathrm{O}_{4} @ \mathrm{PEG}$ were acquired through a 1.5 T MRI used in clinic (Siemens, Avanto, Germany).

2.5. Heat Induction Property under ACMF. The heating experiments of $\mathrm{Fe}_{3} \mathrm{O}_{4} @ \mathrm{PEG}$ with four different sizes were measured using a radio frequency heating system (Shuangping SPG-06-II, China). The samples with iron concentration of $1 \mathrm{mg} \mathrm{ml}^{-1}$ in water solution were placed in the vertical copper coil under an alternating current magnetic field (ACMF, $420 \mathrm{kHz}, 15 \mathrm{~A}, 2.25 \mathrm{kA} / \mathrm{m}$ ). The temperature-time curve was tested by a fiber optic sensor (FISO, Canada). Specific absorption rate (SAR) value was applied to quantify the heating efficiency of MION under ACMF. The value of SAR can be calculated using the following formula: $\mathrm{SAR}=C_{\mathrm{w}}(d T / d t)\left(m_{\mathrm{s}} / m_{\mathrm{Fe}}\right)$, where $C_{\mathrm{w}}$ is the specific heat capacity of the solution (specific heat capacity of water is $4.18 \mathrm{~kJ} \mathrm{~kg}^{-1} \mathrm{~K}^{-1}$ ); $d T / d t$ stands for the initial slope of the temperature versus time curve; $m_{\mathrm{s}}$ is the mass of the whole solution, and $m_{\mathrm{Fe}}$ means the mass of the iron in the solution [24].

2.6. Cellular Cytotoxicity and Phagocytosis of $\mathrm{Fe}_{3} \mathrm{O}_{4} @ P E G$. HUVECs and 4T1 cells were cultured in PRMI-1640 medium supplemented with $10 \% \mathrm{FBS}$ and $1 \%$ penicillin-streptomycin at $37^{\circ} \mathrm{C}$ and $5 \% \mathrm{CO}_{2}$ in a humidified incubator. RAW264.7 macrophages were cultured in DMEM medium supplemented with $10 \% \mathrm{FBS}$ and $1 \%$ penicillin-streptomycin at $37^{\circ} \mathrm{C}$ and $5 \% \mathrm{CO}_{2}$ in a humidified incubator.

The 4T1 breast cancer cells and HUVECs were used for assessing the cytotoxicity of PEGylated MION of four sizes. These two cell lines were, respectively, seeded in 96-well plates with $10^{4}$ cells per well $(n=4)$ and grew overnight. Subsequently, $\mathrm{Fe}_{3} \mathrm{O}_{4} @ \mathrm{PEG}(14,18,22$, and $26 \mathrm{~nm})$ were added, respectively, with the final concentration of $0-100 \mu \mathrm{g} \mathrm{ml}^{-1}$. After $24 \mathrm{~h}$ cocultivation at $37^{\circ} \mathrm{C}, \mathrm{CCK} 8$ assay was used to measure the cell viability.

The nonspecific phagocytosis of $\mathrm{Fe}_{3} \mathrm{O}_{4} @ \mathrm{PEG}$ of four sizes was investigated by RAW264.7 macrophages which were incubated in several 12 -well plates. After adherence, the cells were, respectively, incubated with PEGylated MION of four different sizes and MDSA-modified MION $\left(\mathrm{Fe}_{3} \mathrm{O}_{4} @ \mathrm{DMSA}, 10 \mathrm{~nm}\right)$ at a concentration of $100 \mu \mathrm{g} \mathrm{ml} \mathrm{m}^{-1}$ at $37^{\circ} \mathrm{C}$. $\mathrm{Fe}_{3} \mathrm{O}_{4} @ \mathrm{DMSA}$ (2,3-dimercaptosuccinic acid) was synthesized according to the previous work [23]. After coculture of $4 \mathrm{~h}$ or $8 \mathrm{~h}$, the culture solution was removed and the cells were washed with phosphate-buffered saline (PBS), fixed with $4 \%$ paraformaldehyde. Then the iron phagocytized by macrophages was detected by Prussian blue staining.

2.7. Animal Protocol. All animal care and experiments were performed in compliance with Institutional Animal Care and Use Committee of Southeast University, Nanjing, China. The tumor models were established by injection of murine breast cancer cells $\left(2 \times 10^{6} 4 \mathrm{~T} 1\right.$ cells in $150 \mu \mathrm{l}$ cell culture medium) into the right flanks of female BALB/c mice (4-6 weeks old, 18-20 g in weight) which were obtained from the Model Animal Research Center of Southeast University. The mice with tumors underwent MRI after subcutaneous implantation of 8 days when the tumor volume reached about $100 \mathrm{~mm}^{3}$.

2.8. In Vivo MRI of Tumor. In vivo tumor MRI was performed by a 7.0 T micro-MRI scanner (PharmaScan, Brukers, Germany) equipped with a $38 \mathrm{~mm}$ circular coil and a respiratory monitoring system. The parameters of $\mathrm{T}_{2}{ }^{*}$-weighted imaging were as follows: $\mathrm{TR}=400.0 \mathrm{~ms}$, $\mathrm{TE}=8.0 \mathrm{~ms}, \quad \mathrm{FA}=30.0 \mathrm{deg}$, slice orient: axial, FOV read $=3.2 \mathrm{~cm} \times 3.2 \mathrm{~cm}$, slices $=15$, and slice thickness $=$ $1 \mathrm{~mm}$. Twelve tumor-bearing mice were randomly divided into four groups for MRI of $\mathrm{Fe}_{3} \mathrm{O}_{4} @ \mathrm{PEG}$ of four sizes $(n=3)$. To compare the enhancement effect of signal intensity in the tumor site, MRI was conducted before and $3 \mathrm{~h}$ after intravenous injection of $\mathrm{Fe}_{3} \mathrm{O}_{4} @ \mathrm{PEG}$ with different sizes at a dosage of $10 \mathrm{mg} \mathrm{kg}^{-1}$ by tail vein.

2.9. Histological Examination. After MR imaging experiment, tumors and main organs of mice injected of normal saline and $\mathrm{Fe}_{3} \mathrm{O}_{4} @ P E G$ with four different sizes were excised and fixed in $10 \%$ neutral formalin, processed into paraffin for analysis of distribution of PEGylated MION and hematoxylin and eosin (H\&E) staining. The tissue slices were then stained by Prussian blue for iron detection and nuclear fast red for cell nucleus.

2.10. Statistical Analysis. The data were expressed as mean \pm SE. Statistical differences were conducted using Student's $t$-test. The situation of $P<0.05$ was considered to have significant difference. The symbol of $*$ represented $P<0.05$ and $* *$ represented $P<0.01$.

\section{Results and Discussion}

3.1. Characterization of $\mathrm{Fe}_{3} \mathrm{O}_{4} @ O A$ and $\mathrm{Fe}_{3} \mathrm{O}_{4} @ P E G$. The $\mathrm{Fe}_{3} \mathrm{O}_{4} @ \mathrm{OA}$ with four different sizes were prepared by a thermal decomposition method, and the morphology was characterized by TEM. Figure S1 showed that the MIONs of 14,18 , and $22 \mathrm{~nm}$ were uniform while the size of $26 \mathrm{~nm}$ was not so homogeneous. During the preparation of MION, it was found that the synthesis of uniform nanoparticles becomes difficult when the size is larger than $22 \mathrm{~nm}$ using this method. As the products of the thermal decomposition method were hydrophobic, biocompatible DSPE-PEG2000 was used for surface modification. As shown in Figure 1, all the nanoparticles of four different sizes were successfully modified without apparent agglomeration, where a thin layer of DSPE-PEG2000 was visible. The DLS data showed that the hydrodynamic diameters of the as-synthesized MION with different TEM sizes $(14,18,22$, and $26 \mathrm{~nm})$ were $24,28,33$, and $38 \mathrm{~nm}$, respectively (Figure $2(\mathrm{a})$ ). What is more, $\mathrm{Fe}_{3} \mathrm{O}_{4} @ \mathrm{PEG}$ of the four sizes all exhibited excellent stability in aqueous 


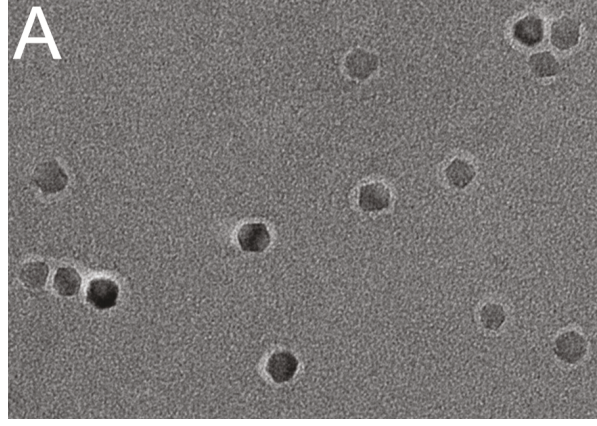

(a)

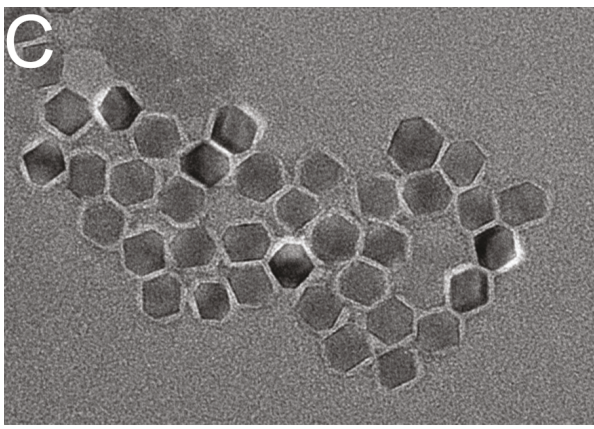

(c)

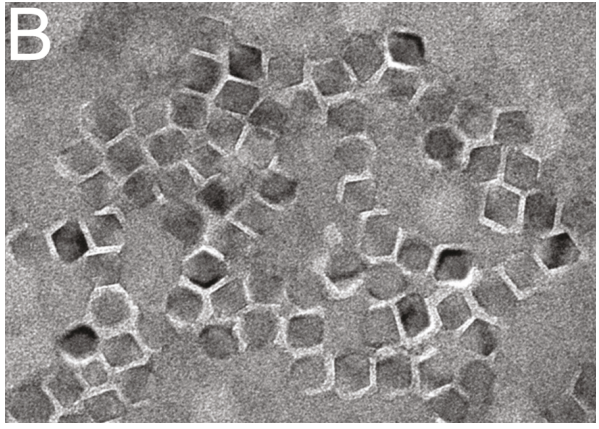

(b)

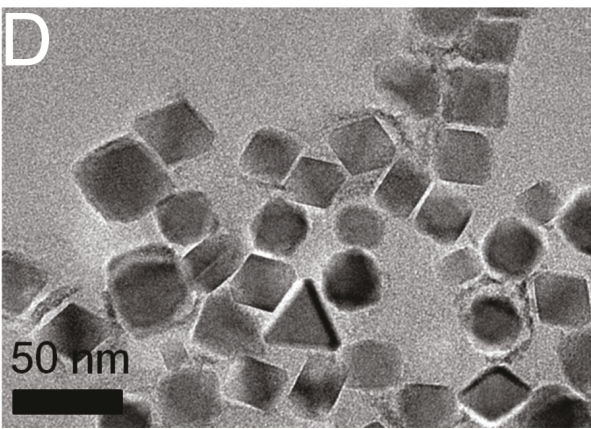

(d)

Figure 1: TEM images of $\mathrm{Fe}_{3} \mathrm{O}_{4} @ P E G$ of (a) $14 \mathrm{~nm}$, (b) $18 \mathrm{~nm}$, (c) $22 \mathrm{~nm}$, and (d) $26 \mathrm{~nm}$.
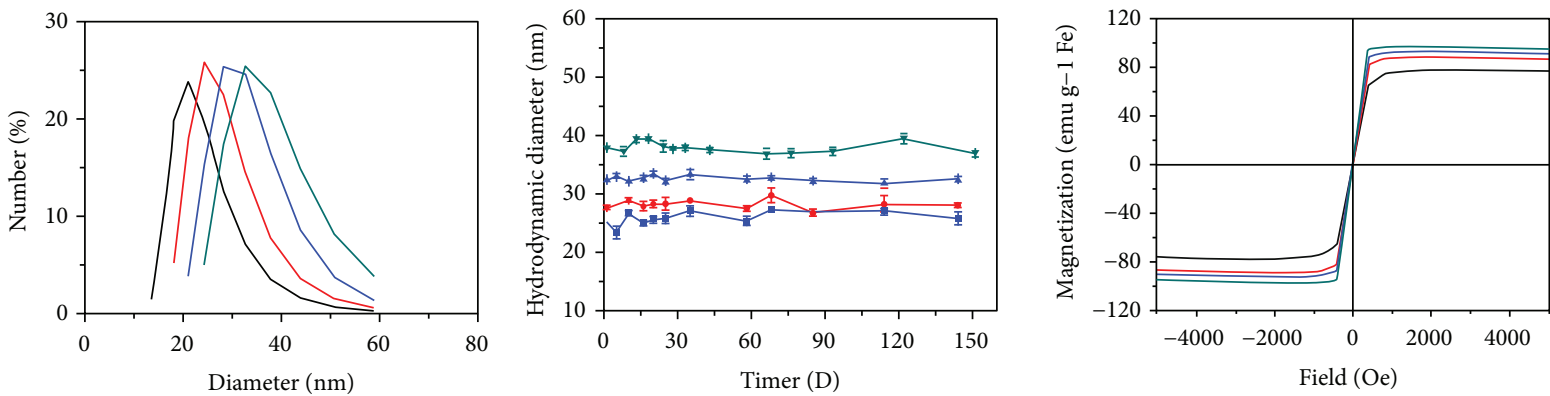

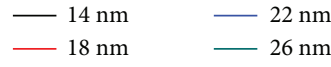

(a)

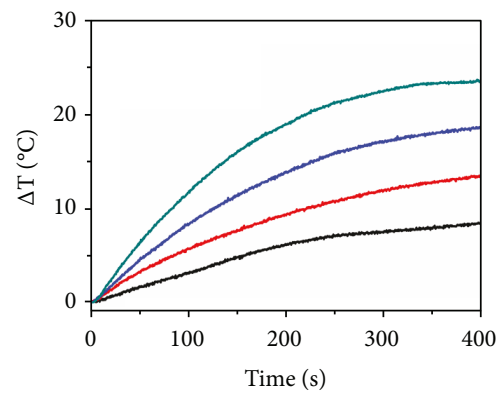

$\begin{array}{rr}-14 \mathrm{~nm} 167 \mathrm{w} / \mathrm{g} & -22 \mathrm{~nm} 425 \mathrm{w} / \mathrm{g} \\ -18 \mathrm{~nm} 306 \mathrm{w} / \mathrm{g} & -26 \mathrm{~nm} 625 \mathrm{w} / \mathrm{g}\end{array}$

(d)

$$
\begin{aligned}
& \longrightarrow 14 \mathrm{~nm} \quad \longrightarrow 22 \mathrm{~nm} \\
& \rightarrow 18 \mathrm{~nm} \quad \longrightarrow 26 \mathrm{~nm}
\end{aligned}
$$

(b)

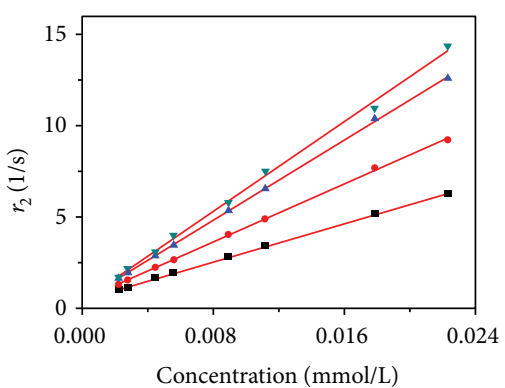

- $14 \mathrm{~nm}$

- $18 \mathrm{~nm}$

(e)
$\Delta 22 \mathrm{~nm}$

$\checkmark 26 \mathrm{~nm}$

e)

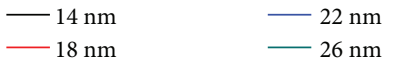

(c)

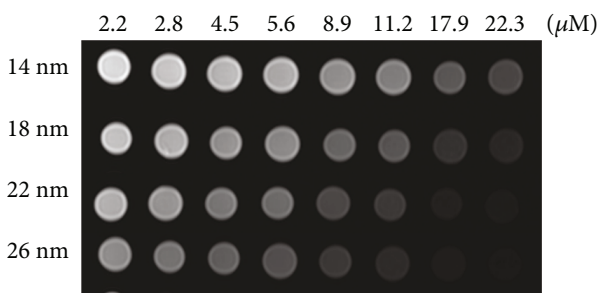

Figure 2: (a) DLS data of $\mathrm{Fe}_{3} \mathrm{O}_{4} @ P E G$ with different sizes in water. (b) The stability assessment by monitoring average hydrodynamic diameters of $\mathrm{Fe}_{3} \mathrm{O}_{4} @ \mathrm{PEG}$ in water during 5 months. The data of $(\mathrm{b})$ is shown as mean $\pm \mathrm{SE}(n=3)$. (c) Hysteresis loops of Fe $\mathrm{O}_{4} @ \mathrm{PEG}$ with different sizes. (d) Temperature-time curves of $\mathrm{Fe}_{3} \mathrm{O}_{4} @ \mathrm{PEG}$ in an aqueous phase $(1 \mathrm{mg} \mathrm{Fe} / \mathrm{ml})$ under ACMF $(420 \mathrm{kHz}, 15 \mathrm{~A}, 2.25 \mathrm{kA} / \mathrm{m})$. (e) Relaxation rate and (f) $\mathrm{T}_{2}$-weighted $\mathrm{MR}$ images of $\mathrm{Fe}_{3} \mathrm{O}_{4} @ \mathrm{PEG}$ with different sizes upon iron concentration measured by a $1.5 \mathrm{~T} \mathrm{MR}$ scanner. 

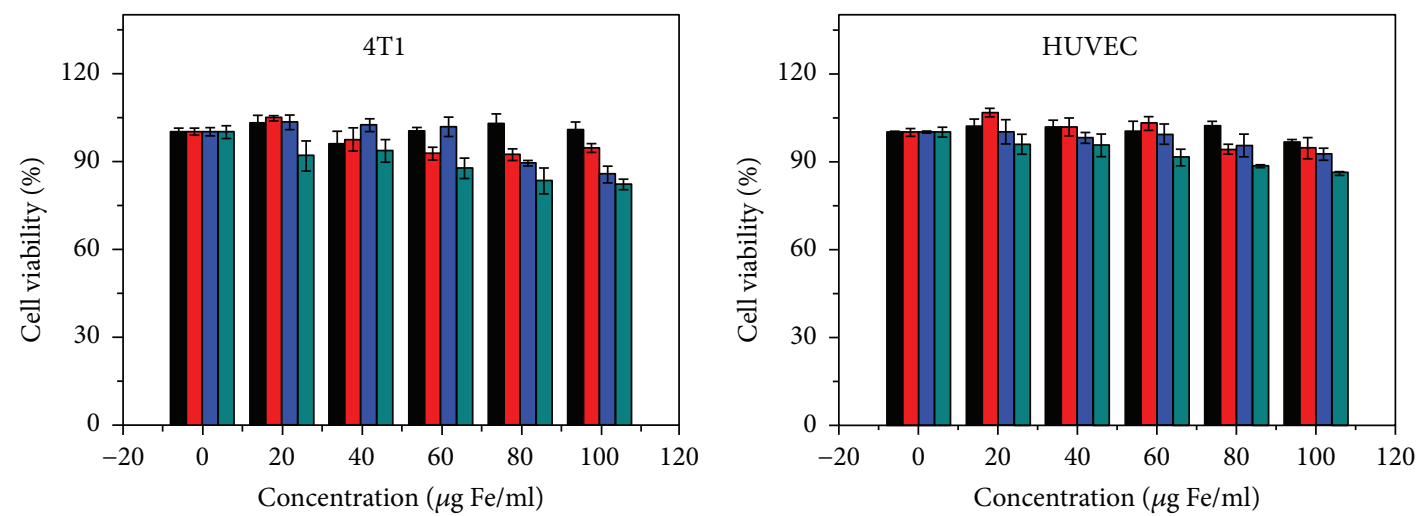

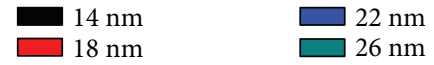

(a)

$4 \mathrm{~h}$
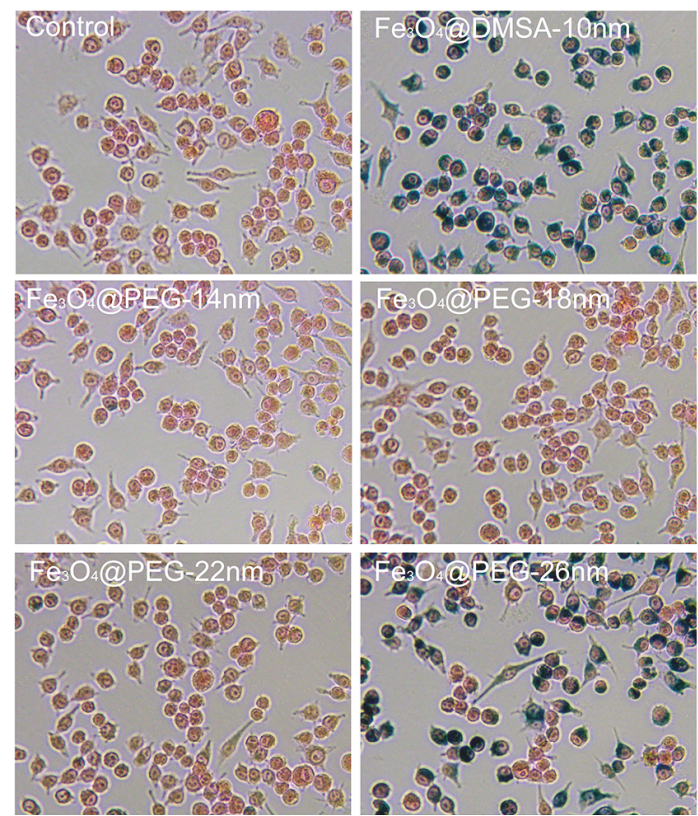

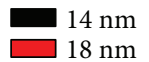

$\square 22 \mathrm{~nm}$
$\square 26 \mathrm{~nm}$

(b)

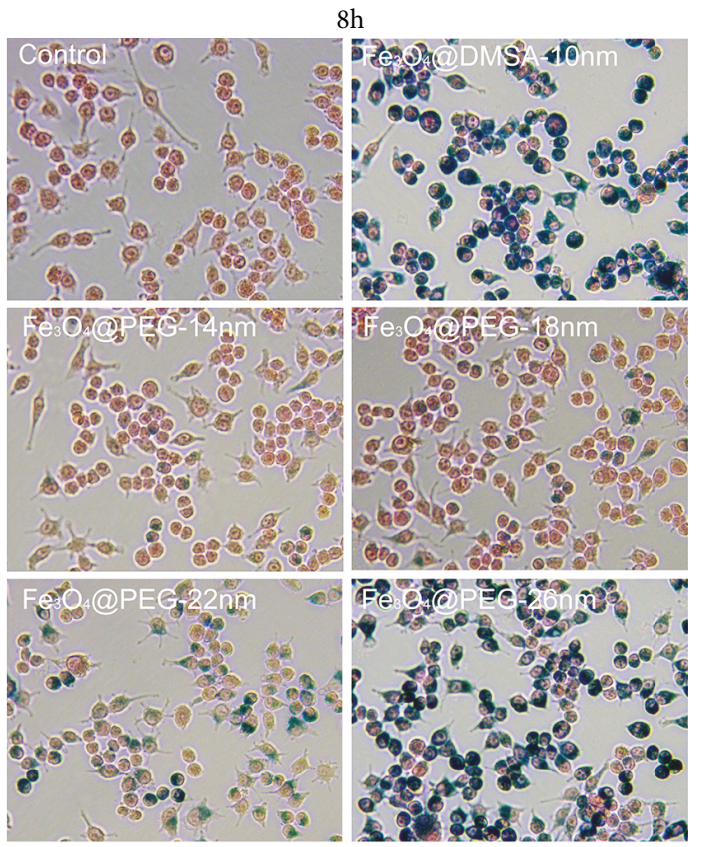

(c)

FIGURE 3: In vitro cytotoxicity test of $\mathrm{Fe}_{3} \mathrm{O}_{4} @ \mathrm{PEG}$ with different sizes against (a) 4T1 cells and (b) HUVECs. The cellular viability was measured by CCK8 assay after cocultivation with various concentrations of Fe for $24 \mathrm{~h}(n=4)$. (c) Phagocytosis testing with Prussian blue and nuclear fast red double staining images (200x) of macrophages RAW 264.7 after $4 \mathrm{~h}$ and $8 \mathrm{~h}$ treatment with $\mathrm{Fe}_{3} \mathrm{O}_{4} @ \mathrm{PEG}$ of different sizes and $\mathrm{Fe}_{3} \mathrm{O}_{4} @ \mathrm{DMSA}$ at the concentrations of $100 \mu \mathrm{g} \mathrm{Fe} / \mathrm{ml}$.

solution during a long period of time about 5 months (Figure 2(b)).

In addition to colloidal stability, the magnetic property of MION is another crucial factor for in vivo biomedical applications. The saturation magnetization $\left(M_{\mathrm{s}}\right)$ of $\mathrm{Fe}_{3} \mathrm{O}_{4} @ \mathrm{PEG}$ increased with size, and the hysteresis loop exhibited superparamagnetic behavior (Figure 2(c)). The $M_{\mathrm{s}}$ of the four sizes $(14,18,22$, and $26 \mathrm{~nm})$ was $78,88,92$, and $97 \mathrm{emu} \mathrm{g}^{-1} \mathrm{Fe}$ at room temperature $(300 \mathrm{~K})$, respectively. It was worth mentioning that the $M_{\mathrm{s}}$ tended to have impact on magnetic heating and MRI contrast effect of MION [25-27]. In order to assess the magnetically induced heating efficiency under ACMF, SAR value was used as an evaluation criterion. As expected, the measured SAR values $(167,306,425$, and $\left.625 \mathrm{~W} \mathrm{~g}^{-1} \mathrm{Fe}\right)$ increased monotonically with MION size $(14,18,22$, and $26 \mathrm{~nm}$ ) (Figure 2(d)), which was accord with the previous literature [16]. The high SAR value indicated that the MIONs have potential as magnetic fluid hyperthermia agents for magnetic hyperthermia of tumors, which makes it possible to realize diagnosis and treatment simultaneously. Moreover, the contrast enhancement capability of MION was measured in vitro. As shown in Figure 2(f), the MR signal intensity was attenuated as the concentration and size of MION increased. Their corresponding relaxivity coefficient $\left(r_{2}\right)$ values were, respectively, calculated as $262,398,549$, and $615 \mathrm{mM}^{-1} \mathrm{~s}^{-1}$ (Figure 2(e)), which was much larger than Feridex $\left(133 \mathrm{mM}^{-1} \mathrm{~s}^{-1}\right)$ in the previous report [28]. The high $r_{2}$ values ensured the effectiveness 
14

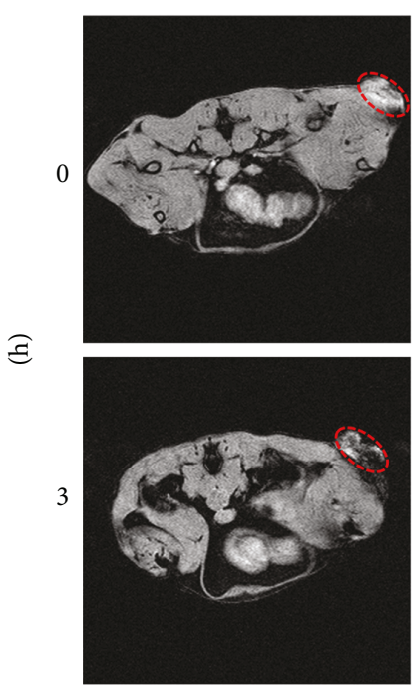

18
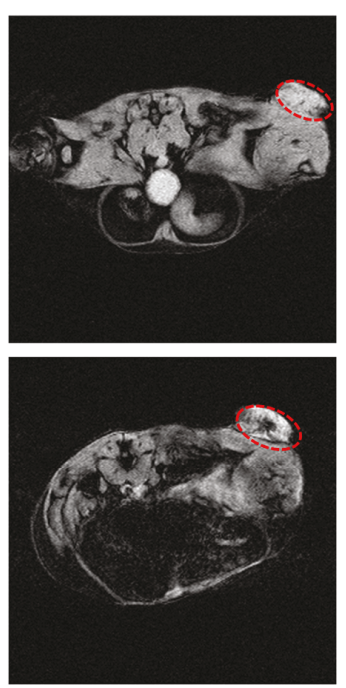

22
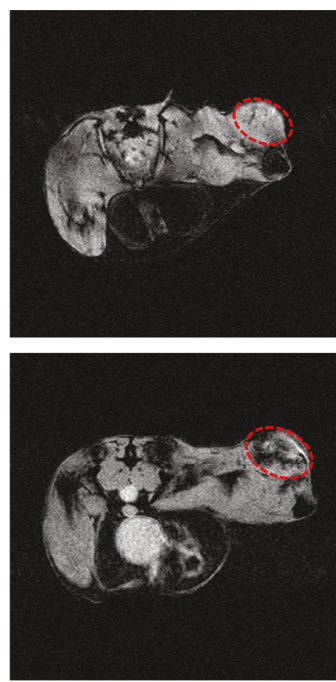

26
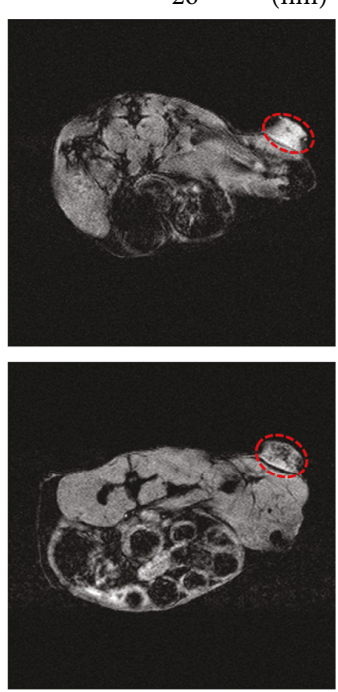

(a)

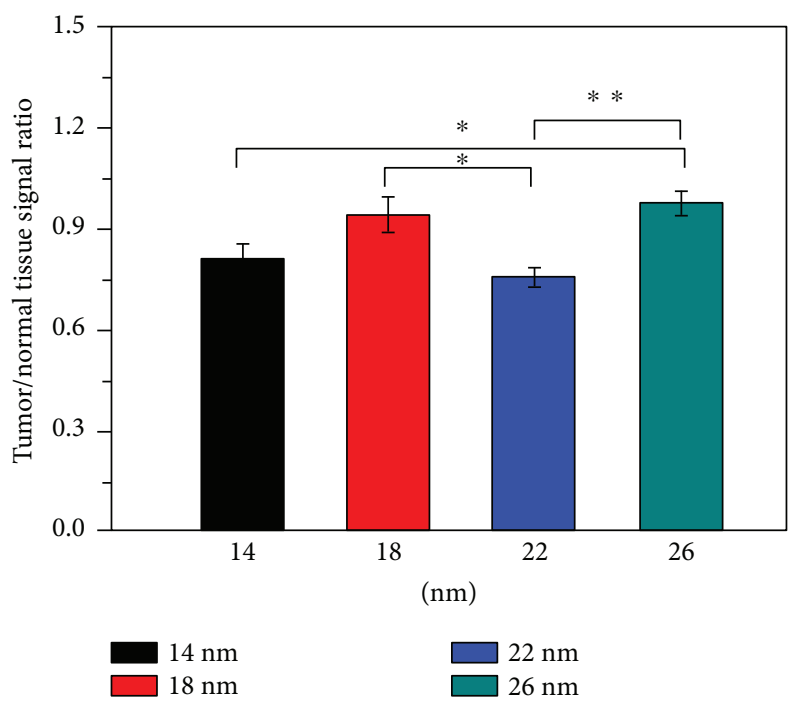

(b)

Figure 4: (a) $\mathrm{T}_{2}{ }^{*}$-weighted MR images of mouse tumors obtained before and $3 \mathrm{~h}$ after injection of $\mathrm{Fe}_{3} \mathrm{O}_{4} @ \mathrm{PEG}$ with different sizes (10 mg Fe/kg body weight) by a $7 \mathrm{~T}$ MR scanner. The red dotted line represented the tumor site. (b) TNR (tumor/normal tissue signal ratio) value measured from MR images acquired $3 \mathrm{~h}$ postinjection of $\mathrm{Fe}_{3} \mathrm{O}_{4} @ \mathrm{PEG}$ with different sizes. The data of (b) is shown as mean \pm SE $(n=3)$. The asterisk indicated statistical significance $\left({ }^{*} P<0.05,{ }^{* *} P<0.01\right)$.

of contrast enhancement in MR imaging at a relatively low dosage of $\mathrm{Fe}_{3} \mathrm{O}_{4} @ \mathrm{PEG}$.

3.2. Cellular Cytotoxicity and Macrophage Phagocytosis of $\mathrm{Fe}_{3} \mathrm{O}_{4} @ P E G$. As an MRI contrast agent, it was necessary to evaluate the toxicity of $\mathrm{Fe}_{3} \mathrm{O}_{4} @ \mathrm{PEG}$ for further applications in the living body. CCK8 assay was used to assess the cytotoxicity of $\mathrm{Fe}_{3} \mathrm{O}_{4} @ \mathrm{PEG}$ with four sizes against $4 \mathrm{~T} 1$ cells and HUVECs in response to a series of concentrations of iron from 0 to $100 \mu \mathrm{g} \mathrm{ml}^{-1}$. As shown in Figures 3(a) and 3(b), the treatment of $4 \mathrm{~T} 1$ cells and HUVECs with $\mathrm{Fe}_{3} \mathrm{O}_{4} @ \mathrm{PEG}$ for $24 \mathrm{~h}$ did not cause appreciable toxicity even at the concentration as high as $100 \mu \mathrm{g} \mathrm{ml}^{-1}$. These results suggested that the PEGylation of MION with FDA-approved
DSPE-PEG make them safe to be applied as a $\mathrm{T}_{2}$-weighted MRI contrast agent.

RAW 264.7 macrophage phagocytosis experiments were conducted to assess the capability of $\mathrm{Fe}_{3} \mathrm{O}_{4} @ \mathrm{PEG}$ with four different sizes to escape the nonspecific uptake by a reticuloendothelial system (RES). As it was easy to be phagocytosed by macrophages, DMSA-modified MION was generally used for positive comparison [29, 30]. After incubation with $\mathrm{Fe}_{3} \mathrm{O}_{4} @ \mathrm{PEG}$ or $\mathrm{Fe}_{3} \mathrm{O}_{4} @$ DMSA for 4 and $8 \mathrm{~h}$, the MIONs phagocytosed by macrophages were qualitatively determined by Prussian blue staining (blue marking). It can be observed in Figure 3(c) that most of the macrophages incubated with $\mathrm{Fe}_{3} \mathrm{O}_{4} @ \mathrm{DMSA}$ for both $4 \mathrm{~h}$ and $8 \mathrm{~h}$ were stained blue, indicating that DMSA modification could not avoid nonspecific 


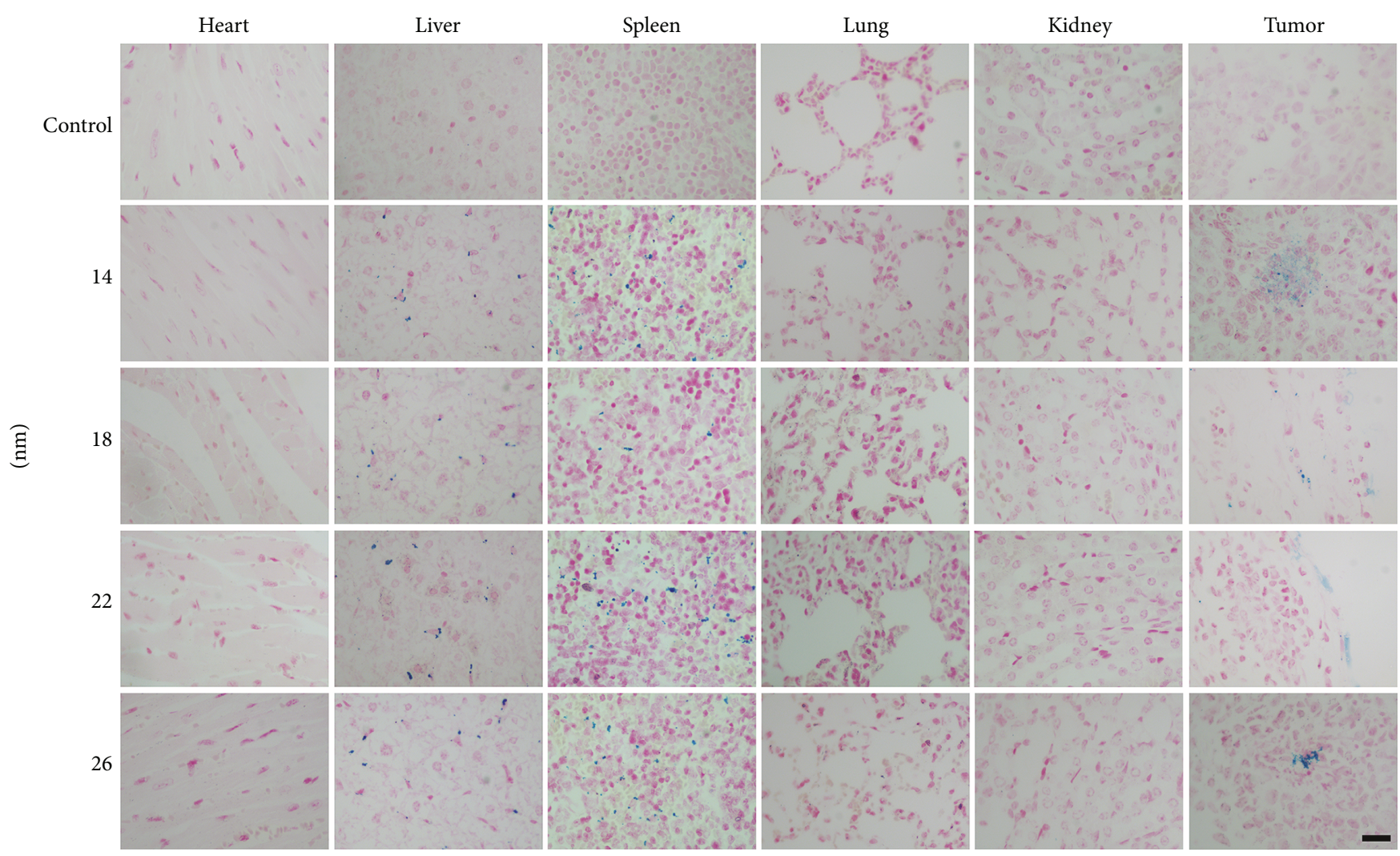

FIGURE 5: Nuclear fast red and Prussian blue double staining images (400x) of mouse organs and tumors $24 \mathrm{~h}$ postinjection of normal saline and $\mathrm{Fe}_{3} \mathrm{O}_{4} @ \mathrm{PEG}$ of different sizes. The black bar represented $20 \mu \mathrm{m}$.

uptake. Nevertheless, $\mathrm{Fe}_{3} \mathrm{O}_{4} @ P E G$ were phagocytosed both in time-dependent and size-dependent ways. For $4 \mathrm{~h}$ incubation, there was no blue marking detected in the $\mathrm{Fe}_{3} \mathrm{O}_{4} @ P E G$ group of 14, 18, and $22 \mathrm{~nm}$ except $26 \mathrm{~nm}$. However, after $8 \mathrm{~h}$ cocultivation, the phagocytosis of macrophages increased monotonically with MION size. These results indicated that PEGylation of MION could dramatically enhance the ability to escape nonspecific uptake of macrophages, but this effect became limited when the size of MION was as large as $26 \mathrm{~nm}$.

3.3. In Vivo $\mathrm{T}_{2}{ }^{*}$-Weighted $M R I$ Using $\mathrm{Fe}_{3} \mathrm{O}_{4} @ P E G$ with Different Sizes. Although the magnetic property of MION described as $M_{s}$, SAR, and $r_{2}$ values was measured in vitro, MR imaging of the living body should be conducted to further assess the application potentials of $\mathrm{Fe}_{3} \mathrm{O}_{4} @ P E G$ with four sizes as an MRI contrast agent. BABL/c mice bearing 4T1 tumors were intravenously injected with $\mathrm{Fe}_{3} \mathrm{O}_{4} @ \mathrm{PEG}$ of $14,18,22$, and $26 \mathrm{~nm}$, respectively. The $\mathrm{T}_{2}{ }^{*}$-weighted MR images of tumor region were recorded before and $3 \mathrm{~h}$ postinjection of the contrast agent at a dosage of $10 \mathrm{mg} \mathrm{Fe}$ per kilogram body weight. As shown in Figure 4(a), there was distinct decrease of the signal intensity in the tumor area of mice, respectively, treated with $\mathrm{Fe}_{3} \mathrm{O}_{4} @ P E G$ of four sizes. To quantitatively assess the contrast imaging effect resulted from $\mathrm{Fe}_{3} \mathrm{O}_{4} @ \mathrm{PEG}$, the enhancement degree of tumor tissue on MR images was analyzed as TNR (tumor/normal tissue signal ratio) values between the tumor and the adjacent normal muscle [20]. It means that small TNR values represented favorable imaging effect. After quantitative analysis, it was observed that although $\mathrm{Fe}_{3} \mathrm{O}_{4} @ \mathrm{PEG}$ of all the four sizes had imaging function, the contrast enhancement effect was different. It has been shown in Figure 4(b) that the MION of $22 \mathrm{~nm}$ displayed the best contrast effect followed by that of $14 \mathrm{~nm}$, while the MION of $26 \mathrm{~nm}$ exhibited the worst.

In combination with the previous results involving characterization and phagocytosis test, as the enlargement of MION size, the magnetic property improved while the capacity of antiphagocytosis decreased. Collectively, there should be optimal mediation between the performance and antiphagocytosis of MION for in vivo MR imaging as a contrast agent. The enhanced MRI contrast of the MION of $22 \mathrm{~nm}$ in the tumor may be a combined result of the size-dependent property and captured by macrophages. Therefore, the size of $22 \mathrm{~nm}$ might be more suitable for imaging, as well as holds a great potential for tumor hyperthermia in consideration of the relatively high heating efficiency under ACMF.

3.4. In Vivo Distribution of $\mathrm{Fe}_{3} \mathrm{O}_{4} @ P E G$. In order to verify the in vivo distribution of $\mathrm{Fe}_{3} \mathrm{O}_{4} @ \mathrm{PEG}$, the tumors and main organs were harvested $24 \mathrm{~h}$ postinjection of normal saline or $\mathrm{Fe}_{3} \mathrm{O}_{4} @$ PEG of four different sizes followed by Prussian blue and nuclear fast red double staining. Figure 5 showed that the distribution of $\mathrm{Fe}_{3} \mathrm{O}_{4} @ \mathrm{PEG}$ was similar for four different sizes, and the MION mainly distributed in tumor and organs in the liver and spleen. On the account of the 
low dosage of injection, there was a small quantity of blue spots observed in the abovementioned tissues. Furthermore, $\mathrm{H} \& \mathrm{E}$ staining displayed no obvious damage of main organs (Figure S2), which further verified the safety of $\mathrm{Fe}_{3} \mathrm{O}_{4} @ P E G$ as a contrast agent applied in the living body.

\section{Conclusion}

In conclusion, we have synthesized $\mathrm{MION}$ with four different sizes by a thermal decomposition method and presented a precise study on size-dependent properties of the MION for further in vivo $\mathrm{MR}$ imaging. Through measurement of magnetic properties, these MION exhibited favorable performance depending on size. In vitro cell experiments confirmed the biocompatibility of these MIONs and the capacity of antiphagocytosis except the MION with the size of $26 \mathrm{~nm}$. After in vivo imaging, the MION of $22 \mathrm{~nm}$ was identified to be the optimal size applied as a contrast agent for $\mathrm{T}_{2}{ }^{*}$-weighted MR imaging. We also concluded that, for size selection of magnetic nanoparticles in in vivo applications, it is important to consider the balance between the magnetic properties and antiphagocytosis capability.

\section{Data Availability}

The underlying data related to this article are available upon request.

\section{Conflicts of Interest}

The authors declare no competing interests regarding the publication of this paper.

\section{Acknowledgments}

This research was supported by the National Key Research and Development Program of China (no. 2017YFA0205502), National Natural Science Foundation of China (nos. 81571806, 81671820, and 81301870), the Science and Technology Support Program of Jiangsu Province (no. BE2017763), the Jiangsu Provincial Special Program of Medical Science (no. BL2013029), and the Fundamental Research Funds for the Central Universities.

\section{Supplementary Materials}

Supplementary 1. Figure S1 is the TEM images of the hydrophobic magnetic iron oxide nanoparticles $\left(\mathrm{Fe}_{3} \mathrm{O}_{4} @ \mathrm{OA}\right)$ of four different sizes. (A) $14 \mathrm{~nm}$, (B) $18 \mathrm{~nm}$, (C) $22 \mathrm{~nm}$, and (D) $26 \mathrm{~nm}$.

Supplementary 2. Figure S2 is HE staining images of mouse main organs after intravenous injection of normal saline (control) and PEGylated magnetic iron oxide nanoparticles $\left(\mathrm{Fe}_{3} \mathrm{O}_{4} @ \mathrm{PEG}\right)$ of four different sizes for $24 \mathrm{~h}$.

\section{References}

[1] Y. Lu, Y.-J. Xu, G.-b. Zhang et al., "Iron oxide nanoclusters for $T_{1}$ magnetic resonance imaging of non-human primates," Nature Biomedical Engineering, vol. 1, no. 8, pp. 637-643, 2017.
[2] N. Lee, Y. Choi, Y. Lee et al., "Water-dispersible ferrimagnetic iron oxide nanocubes with extremely high $r_{2}$ relaxivity for highly sensitive in vivo MRI of tumors," Nano Letters, vol. 12, no. 6, pp. 3127-3131, 2012.

[3] J.-H. Lee, Y.-M. Huh, Y.-w. Jun et al., "Artificially engineered magnetic nanoparticles for ultra-sensitive molecular imaging," Nature Medicine, vol. 13, no. 1, pp. 95-99, 2007.

[4] K. Hayashi, M. Nakamura, W. Sakamoto et al., "Superparamagnetic nanoparticle clusters for cancer theranostics combining magnetic resonance imaging and hyperthermia treatment," Theranostics, vol. 3, no. 6, pp. 366-376, 2013.

[5] T. Kobayashi, "Cancer hyperthermia using magnetic nanoparticles,” Biotechnology Journal, vol. 6, no. 11, pp. 1342-1347, 2011.

[6] S. A. Stanley, J. E. Gagner, S. Damanpour, M. Yoshida, J. S. Dordick, and J. M. Friedman, "Radio-wave heating of iron oxide nanoparticles can regulate plasma glucose in mice," Science, vol. 336, no. 6081, pp. 604-608, 2012.

[7] C. Hoffmann, E. Mazari, S. Lallet et al., "Spatiotemporal control of microtubule nucleation and assembly using magnetic nanoparticles," Nature Nanotechnology, vol. 8, no. 3, pp. 199-205, 2013.

[8] B. Hu, J. Dobson, and A. J. El Haj, "Control of smooth muscle $\alpha$-actin (SMA) up-regulation in HBMSCs using remote magnetic particle mechano-activation," Nanomedicine: Nanotechnology, Biology and Medicine, vol. 10, no. 1, pp. 45-55, 2014.

[9] G. Bao, S. Mitragotri, and S. Tong, "Multifunctional nanoparticles for drug delivery and molecular imaging," Annual Review of Biomedical Engineering, vol. 15, no. 1, pp. 253-282, 2013.

[10] Y. Namiki, T. Namiki, H. Yoshida et al., "A novel magnetic crystal-lipid nanostructure for magnetically guided in vivo gene delivery," Nature Nanotechnology, vol. 4, no. 9, pp. 598606, 2009.

[11] Y. Qiu, S. Tong, L. Zhang et al., "Magnetic forces enable controlled drug delivery by disrupting endothelial cell-cell junctions," Nature Communications, vol. 8, article 15594, 2017.

[12] J. Xie, C. Yan, Y. Zhang, and N. Gu, "Shape evolution of "multibranched" Mn-Zn ferrite nanostructures with high performance: a transformation of nanocrystals into nanoclusters," Chemistry of Materials, vol. 25, no. 18, pp. 3702-3709, 2013.

[13] M. Ma, Y. Wu, J. Zhou, Y. Sun, Y. Zhang, and N. Gu, "Size dependence of specific power absorption of $\mathrm{Fe}_{3} \mathrm{O}_{4}$ particles in AC magnetic field," Journal of Magnetism and Magnetic Materials, vol. 268, no. 1-2, pp. 33-39, 2004.

[14] Y. J. Liang, F. Fan, M. Ma et al., "Size-dependent electromagnetic properties and the related simulations of $\mathrm{Fe}_{3} \mathrm{O}_{4}$ nanoparticles made by microwave-assisted thermal decomposition," Colloids and Surfaces A: Physicochemical and Engineering Aspects, vol. 530, pp. 191-199, 2017.

[15] L. Lartigue, C. Innocenti, T. Kalaivani et al., "Water-dispersible sugar-coated iron oxide nanoparticles. An evaluation of their relaxometric and magnetic hyperthermia properties," Journal of the American Chemical Society, vol. 133, no. 27, pp. 10459-10472, 2011.

[16] S. Tong, C. A. Quinto, L. Zhang, P. Mohindra, and G. Bao, "Size-dependent heating of magnetic iron oxide nanoparticles," ACS Nano, vol. 11, no. 7, pp. 6808-6816, 2017.

[17] Y. Lv, "Size dependent magnetic hyperthermia of octahedral $\mathrm{Fe}_{3} \mathrm{O}_{4}$ nanoparticles," RSC Advances, vol. 5, no. 94, pp. 76764-76771, 2015. 
[18] Y. Ma, S. Tong, G. Bao, C. Gao, and Z. Dai, "Indocyanine green loaded SPIO nanoparticles with phospholipid-PEG coating for dual-modal imaging and photothermal therapy," Biomaterials, vol. 34, no. 31, pp. 7706-7714, 2013.

[19] S. Zhang, J. Li, G. Lykotrafitis, G. Bao, and S. Suresh, "Sizedependent endocytosis of nanoparticles," Advanced Materials, vol. 21, no. 4, pp. 419-424, 2009.

[20] L. Chen, J. Xie, H. Wu et al., "Improving sensitivity of magnetic resonance imaging by using a dual-targeted magnetic iron oxide nanoprobe," Colloids and Surfaces B: Biointerfaces, vol. 161, pp. 339-346, 2018.

[21] J. Xie, Y. Zhang, C. Yan et al., "High-performance PEGylated $\mathrm{Mn}-\mathrm{Zn}$ ferrite nanocrystals as a passive-targeted agent for magnetically induced cancer theranostics," Biomaterials, vol. 35, no. 33, pp. 9126-9136, 2014.

[22] J. Xie, C. Yan, Y. Yan et al., "Multi-modal Mn-Zn ferrite nanocrystals for magnetically-induced cancer targeted hyperthermia: a comparison of passive and active targeting effects," Nanoscale, vol. 8, no. 38, pp. 16902-16915, 2016.

[23] M. Song, Y. Zhang, S. Hu et al., "Influence of morphology and surface exchange reaction on magnetic properties of monodisperse magnetite nanoparticles," Colloids and Surfaces A: Physicochemical and Engineering Aspects, vol. 408, pp. 114$121,2012$.

[24] H. Wu, L. Song, L. Chen et al., "Injectable thermosensitive magnetic nanoemulsion hydrogel for multimodal-imagingguided accurate thermoablative cancer therapy," Nanoscale, vol. 9, no. 42, pp. 16175-16182, 2017.

[25] R. Chen, M. G. Christiansen, and P. Anikeeva, "Maximizing hysteretic losses in magnetic ferrite nanoparticles via modeldriven synthesis and materials optimization," ACS Nano, vol. 7, no. 10, pp. 8990-9000, 2013.

[26] S.-h. Noh, W. Na, J.-t. Jang et al., "Nanoscale magnetism control via surface and exchange anisotropy for optimized ferrimagnetic hysteresis," Nano Letters, vol. 12, no. 7, pp. 3716-3721, 2012.

[27] J. t. Jang, H. Nah, J. H. Lee, S. H. Moon, M. G. Kim, and J. Cheon, "Critical enhancements of MRI contrast and hyperthermic effects by dopant-controlled magnetic nanoparticles," Angewandte Chemie, vol. 121, no. 7, pp. 1260-1264, 2009.

[28] N. Lee, H. Kim, S. H. Choi et al., "Magnetosome-like ferrimagnetic iron oxide nanocubes for highly sensitive MRI of single cells and transplanted pancreatic islets," Proceedings of the National Academy of Sciences of the United States of America, vol. 108, no. 7, pp. 2662-2667, 2011.

[29] D. Liu, W. Wu, J. Ling, S. Wen, N. Gu, and X. Zhang, "Effective PEGylation of iron oxide nanoparticles for high performance in vivo cancer imaging," Advanced Functional Materials, vol. 21, no. 8, pp. 1498-1504, 2011.

[30] Z. Jia, L. Song, F. Zang et al., "Active-target $T_{1}$-weighted MR imaging of tiny hepatic tumor via RGD modified ultra-small $\mathrm{Fe}_{3} \mathrm{O}_{4}$ nanoprobes," Theranostics, vol. 6, no. 11, pp. 1780$1791,2016$. 


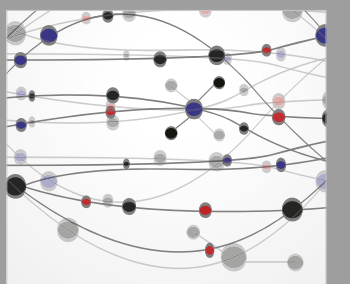

The Scientific World Journal
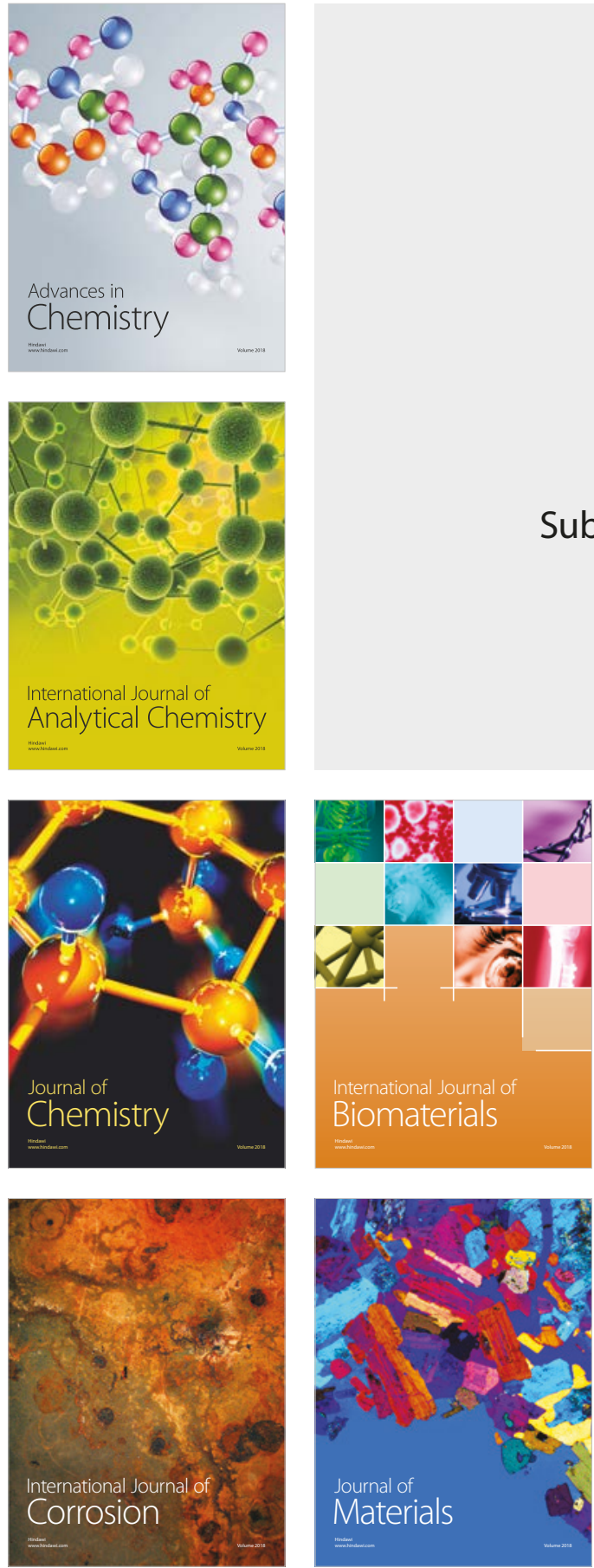

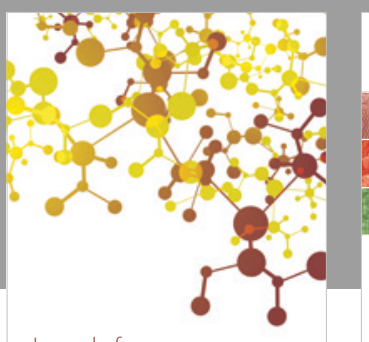

Journal of

Applied Chemistry
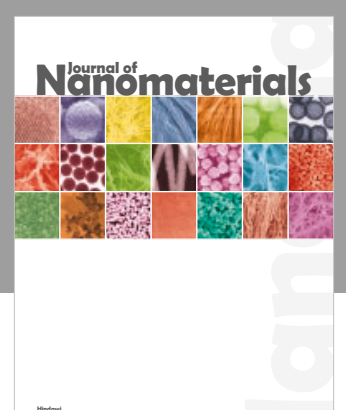

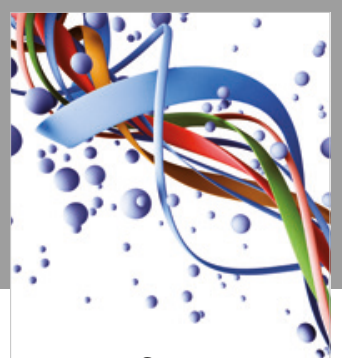

Scientifica

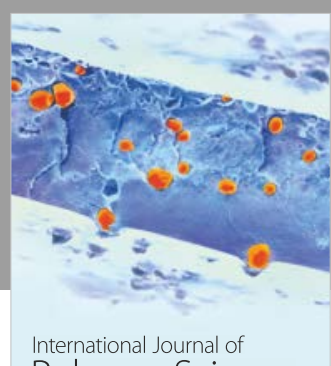

Polymer Science

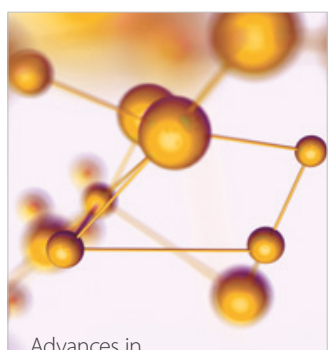

Physical Chemistry
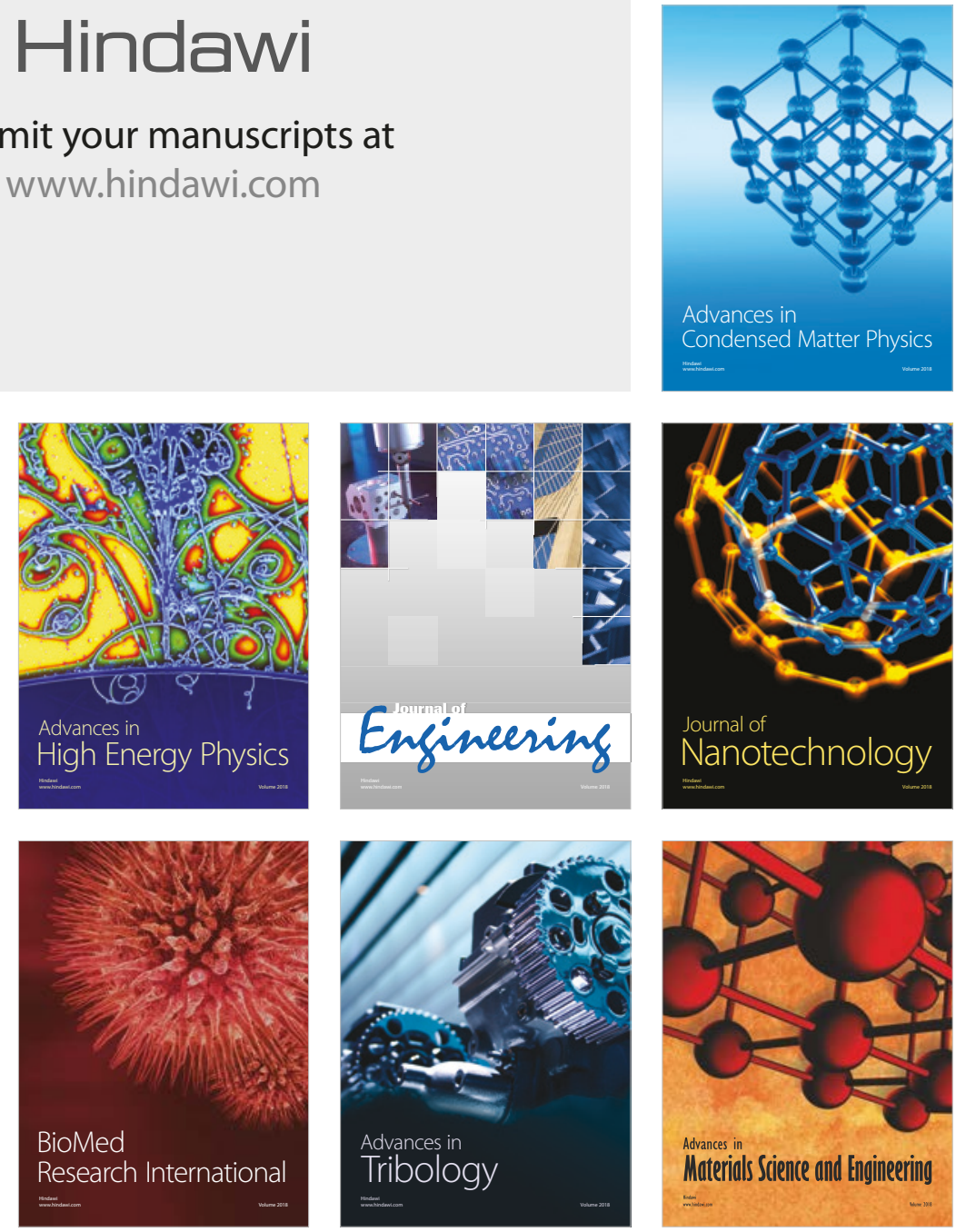